\title{
EDITORIAL
}

\section{Dealing with phthalates in medical devices: a case of primum non nocere (first do no harm)?}

Robert C. Tasker ${ }^{1,2^{*}}$ and Richard M. Sharpe ${ }^{3}$

(C) 2016 Springer-Verlag Berlin Heidelberg and ESICM

\section{Introduction}

Is it possible that we are, inadvertently, harming the longterm health and development of patients receiving intensive care unit (ICU) therapy in infancy? How would we know? What constitutes evidence of harm? What experiment would convince practitioners, toxicologists and public health experts? Would we be able to change some aspect of our practice to prevent such harm?

In a recent article in Intensive Care Medicine, Verstraete et al. [1] report an association between "Iatrogenic exposure to circulating phthalates during treatment in intensive care and attention deficit observed 4 years after pediatric critical illness" in 449 previous recruits to a randomized controlled trial [2]. These results have the potential to become a major focus of controversy and alarm. To better understand how intensivists are to use this information in ICU practice, in this editorial we consider the following: (1) our current understanding of potential phthalate toxicity; (2) the history of research underpinning the study of Verstraete et al. [1] and its characteristics; (3) current regulations on di(2-ethylhexyl)phthalate (DEHP) in medical devices.

\section{Phthalate exposure}

Phthalates are chemical plasticizers used in the production of soft plastics, such as polyvinyl chloride (PVC). DEHP is used to make PVC softer and more pliable and to extend its lifetime. In laboratory animal toxicity studies, certain phthalates, such as DEHP, can act as carcinogens and can also cause fetal death, malformations and

\footnotetext{
*Correspondence: robert.tasker@childrens.harvard.edu

2 Department of Anesthesiology, Perioperative and Pain Medicine, Boston Children's Hospital, 300 Longwood Avenue, Bader 621, Boston, MA 02115, USA

Full list of author information is available at the end of the article
}

reproductive toxicity-although these effects are seen only at levels far in excess of normal human exposure.

In humans, most exposure to DEHP comes from oral intake in our diet $[3,4]$, which has been estimated to range from 1 to $30 \mu \mathrm{g} / \mathrm{kg}$ body weight $/$ day $(\mu \mathrm{g} / \mathrm{kg} /$ day); for infants and children, the 95th percentile is approximately $6-17 \mu \mathrm{g} / \mathrm{kg} /$ day (see: http://ec.europa.eu/health/ scientific_committees/emerging/docs/scenihr_o_047. pdf). The tolerable daily intake (TDI) for DEHP is approximately $48 \mu \mathrm{g} / \mathrm{kg} /$ day based on the no observed adverse effect level (NOAEL) of $4.8 \mathrm{mg} / \mathrm{kg} /$ day for reproductive toxicity in rats that incorporates a safety factor of 100. Phthalates such as DEHP are regulated by legislation; for example, the European Parliament prohibits the use of certain categories of phthalates, including DEHP, in toys and childcare articles intended for children aged $<3$ years (http://eur-lex.europa.eu/legal-content/EN/ TXT/?uri=URISERV:132033).

DEHP is present in plastics used in medical devices, especially in bags and infusion tubing for intravenous solutions and feeding. In adults, DEHP exposure resulting from blood transfusion can reach up to approximately $10,000 \mu \mathrm{g} / \mathrm{kg} /$ day in trauma patients and in those undergoing extracorporeal membrane oxygenation (ECMO). Premature babies on the ICU can be exposed to DEHP at levels similar to the NOAEL ( $4.8 \mathrm{mg} / \mathrm{kg} /$ day) for reproductive toxicity. Neonatal ECMO may result in DEHP exposure totaling 35,000 $\mu \mathrm{g} / \mathrm{kg}$ over 10 days (approx. $3500 \mu \mathrm{g} / \mathrm{kg} /$ day) [5].

\section{The study cohort}

In 2009, Vlasselaers et al. [2] reported results from a prospective, randomized controlled study of intensive insulin therapy for targeting age-adjusted normoglycemia in critically ill infants/children, and its effect on short-term 
outcome. A total of 700 critically ill patients were enrolled in this study, of whom $45 \%$ were aged $<1$ year. Among these children, $74 \%$ underwent cardiac surgery for congenital heart disease and a further $11 \%$ underwent complicated or high-risk surgery or trauma. Forty-two percent received parenteral nutrition, and the median ICU lengthof-stay was 3 days. In 2012, Mesotten et al. [6] reported the neurocognitive developmental follow-up of 456 subjects $(65 \%)$ from the original cohort [1]. These children had on average a 15-point reduction in intelligence quotient 4 years post-ICU treatment [6, 7]. Findings for the Amsterdam Neuropsychological Tasks System (a measure of attention, motor coordination and executive function) were also abnormal. In this recent study of Verstraete et al. [1], neurocognitive outcome was assessed in 449 children (64\% of the 700 critically ill patients recruited to the original study) in relation to the plasma DEHP concentration during the original period of critical illness [2]; $89 \%$ of the children included in this 2016 study had undergone cardiac or other surgery or treatment for trauma. Therefore, follow-up analyses $[1,6]$ involved predominantly postsurgical cases (approx. $89 \%$ ), with approximately $50 \%$ of the patients aged $<1$ year at enrollment.

Before the relationship between DEHP exposure and subsequent neurocognitive outcome can be considered, readers need to be aware of inherent confoundingi.e. the reasons an infant needs ICU care are inherently likely to result in cognitive impairment of the sort present described herein (Table 1) [8-10]. Thus, multiple, interrelated factors are associated with neurocognitive outcomes in the post-ICU population with congenital heart disease. The question which needs to be carefully considered is whether phthalates should be added to this list, or is the "harmful" association with DEHP exposure reported by Verstraete et al. [1] related to factors such as duration of cardiopulmonary bypass and ICU length-ofstay and, consequently, the need for repeated exposure to blood transfusion and blood product bags, or to parenteral nutrition. Furthermore, the method used by these authors to compile their data on DEHP exposure, namely, the product of the plasma concentration on the last day of ICU admission and the ICU length-of-stay [1], means it cannot be related to the TDI and NOAEL for DEHP.

\section{Regulation of DEHP in medical devices}

In 2015 the European Commission adopted an updated report (http://ec.europa.eu/health/scientific_committees/ emerging/docs/scenihr_o_047.pdf), which concluded that there is insufficient evidence to suggest that DEHP-containing medical devices constitute a health risk to patients, whilst recognizing that the use of such devices (essential for survival in ICU) may result in high DEHP exposure. Consequently, the report recommends that materials with low DEHP release potential should be used whenever possible and that replacement of DEHP with other materials should be considered, once lack of toxicity and safety are proven.

\section{Toxicology, pediatric critical care practice and primum non nocere}

Phthalate (mainly DEHP) exposure has been associated with impairment of neurobehavioral development in infants and children in epidemiological studies over the last 6 years, with a focus mainly on attention deficit

Table 1 Perioperative factors associated with adverse neurodevelopmental outcome in infants undergoing cardiac surgery

\begin{tabular}{|c|c|c|}
\hline \multicolumn{3}{|c|}{ Factors associated with neurocognitive outcomes in the post-ICU population with congenital heart disease } \\
\hline Patient & Surgical and anesthetic & Postoperative \\
\hline Race & Sedative/analgesic selection & Low regional cerebral oxygen saturation \\
\hline Sex & Prolonged deep hypothermic circulatory arrest & Inotrope score \\
\hline Birth weight & Duration of aortic cross-clamping & $\begin{array}{l}\text { Use of extracorporeal membrane oxygenation } \\
(\text { ECMO) }\end{array}$ \\
\hline Gestational age & Duration of surgery & Cardiac arrest \\
\hline Chromosomal anomalies & $\begin{array}{l}\text { Cumulative exposure to volatile anesthetics in the } \\
\text { first year }\end{array}$ & Erythropoietin administration \\
\hline Apolipoprotein $\mathrm{E}(A P O E)$ genotype ( $\varepsilon 2$ allele) & Cumulative exposure to opioids in the first year & Care protocols \\
\hline Structural brain immaturity & $\begin{array}{l}\text { Cumulative exposure to benzodiazepines in the } \\
\text { first year }\end{array}$ & Total length of stay in the intensive care unit (ICU) \\
\hline \multicolumn{2}{|l|}{ Specific type of congenital heart disease lesion } & Early oral feeding \\
\hline \multirow[t]{3}{*}{ Maternal education and intelligence } & & Number of days receiving chloral hydrate \\
\hline & & Cumulative dose of benzodiazepines \\
\hline & & Rehabilitation \\
\hline
\end{tabular}


hyperactivity disorders [11-15]; the DEHP exposure in such studies was orders of magnitude lower than those encountered in ICU. Readers should keep in mind that DEHP exposure in non-ICU children derives mainly from diet, raising the possibility of confounding with dietary factors.

The report by Verstraete et al. [1] is the first of its kind in pediatric critical care. The results reported by these authors may lend support to the notion that there is a developmental vulnerability or critical period for exposure to DEHP, with neurocognitive deficit more likely to be associated with younger, critically ill children. However, the subject of the study also impinges on another expanding field of literature, the developmental neurotoxic effects of anesthetic agents [16-18]. Almost $90 \%$ of the population studied by Verstraete et al. [1] received general anesthesia, making it impossible to disentangle neurocognitive associations with DEHP exposure from those associated with cumulative exposure to volatile anesthetics and benzodiazepines [8].

Returning to the question posed at the start of this editorial-it is possible that healthcare providers involved in primary care in the ICU may, inadvertently, harm the long-term health and development of patients receiving ICU therapy in infancy. However, whether such harm is due to exposure to DEHP, to volatile anesthetics or to unmeasured factors, or indeed to an interaction between the multiplicity of known perturbations to homeostasis in a vulnerable, genetically predetermined population, it is not possible to say. We need more studies like the one performed by Verstraete et al. [1] in which large populations of infants and children are followed-up postICU. We also need to shift focus. If DEHP is banned in the manufacture of toys, why do we use it in medical devices for children? Is it beneficial and do these benefits outweigh potential risks? If it is not beneficial, then we should consider it an unwanted substance, providing we have alternative non-toxic plasticizers with which to replace it. Of course, these questions raise the issue of whether we have sufficient safety/toxicity data on any replacements, which will also need large populationbased studies of the type available in the report by Verstraete et al. [1].

\footnotetext{
Author details

${ }^{1}$ Departments of Neurology and Anesthesiology (Pediatric), Harvard Medical School, Boston Children's Hospital, 300 Longwood Avenue, Bader 621, Boston, MA 02115, USA. ${ }^{2}$ Department of Anesthesiology, Perioperative and Pain Medicine, Boston Children's Hospital, 300 Longwood Avenue, Bader 621, Boston, MA 02115, USA. ${ }^{3}$ MRC Centre for Reproductive Health, The Queen's Medical Research Institute, University of Edinburgh, 47 Little France Crescent, Edinburgh EH16 4TJ, UK.
}

\section{Acknowledgments}

R.C. Tasker has no conflicts of interest to report. R.M. Sharpe serves on numerous advisory bodies in Europe and elsewhere in the field of reproductive health and endocrine disruptors.

Received: 17 December 2015 Accepted: 12 January 2016

Published online: 3 February 2016

\section{References}

1. Verstraete S, Vanhorebeek I, Covaci A et al (2016) Circulating phthalates during critical illness in children are associated with long-term attention deficit: a study of a development and a validation cohort. Intensive Care Med. doi:10.1007/s00134-015-4159-5

2. Vlasselaers D, Milants I, Desmet L et al (2009) Intensive insulin therapy for patients in paediatric intensive care: a prospective, randomised controlled study. Lancet 373:547-556

3. Shea KM (2003) American Academy of Pediatrics Committee on Environmental Health. Pediatric exposure and potential toxicity of phthalate plasticizers. Pediatrics 111:1467-1474

4. Halden RU (2010) Plastics and health risks. Annu Rev Public Health 31:179-194

5. Karle VA, Sort BL, Martin GR et al (1997) Extracorporeal membrane oxygenation exposes infants to the plasticizer, di(2-ethylhexyl)phthalate. Crit Care Med 25:696-703

6. Mesotten D, Gielen M, Sterken C et al (2012) Neurocognitive development of children 4 years after critical illness and treatment with tight glucose control. JAMA 308:1641-1650

7. Tasker RC (2012) Pediatric critical care, glycemic control, and hypoglycemia: what is the real target? JAMA 308:1687-1688

8. Andropoulos DB, Ahmad HB, Haq T et al (2014) The association between brain injury, perioperative anesthetic exposure, and 12-month neurodevelopmental outcomes after neonatal cardiac surgery: a retrospective cohort study. Pediatr Anaesth 24:266-274

9. Gaynor JW, Kim DS, Arrington CB et al (2014) Validation of association of the apolipoprotein E $\varepsilon 2$ allele with neurodevelopmental dysfunction after cardiac surgery in neonates and infants. J Thorac Cardiovasc Surg 146:2560-2566

10. Gaynor JW, Stopp C, Wypij D et al (2015) Neurodevelopmental outcomes after cardiac surgery in infancy. Pediatrics 135:816-825

11. Engel SM, Miodovnik A, Canfield RL et al (2010) Prenatal phthalate exposure is associated with childhood behavior and executive functioning. Environ Health Perspect 118:565-571

12. Kim BN, Cho SC, Kim Y et al (2009) Phthalates exposure and attentiondeficit/hyperactivity disorder in school-age children. Biol Psychiatry 66:958-963

13. Chopra V, Harley K, Lahiff M et al (2014) Association between phthalates and attention deficit disorder and learning disability in US children, 6-15 years. Environ Res 128:64-69

14. Kobrosly RW, Evans S, Miodovnik A et al (2014) Prenatal phthalates exposure and neurobehavioral developmental scores in boys and girls 6-10 years of age. Environ Health Perspect 122:521-528

15. Park S, Lee JM, Kim JW et al (2015) Association between phthalates and externalizing behaviors and cortical thickness in children with attention deficit hyperactivity disorder. Psychol Med 45:1601-1612

16. Wang X, Xu Z, Miao CH (2014) Current clinical evidence on the effect of general anesthesia on neurodevelopment in children: an updated systemic review with meta-regression. PLoS One 9:e85760

17. Sinner B, Becke K, Engelhard K (2014) General anaesthetics and the developing brain: an overview. Anaesthesia 69:1009-1022

18. Davidson AJ, Disma N, de Graaff JC et al (2016) Neurodevelopmental outcome at 2 years of age after general anaesthesia and awake-regional anaesthesia in infancy (GAS): an international multicentre, randomised controlled trial. Lancet 387:239-250 